\title{
Impact of Lactic Acid Bacteria on Dendritic Cells from Allergic Patients in an Experimental Model of Intestinal Epithelium
}

\author{
Céline Ratajczak, ${ }^{1,2,3}$ Catherine Duez, ${ }^{1,2,3}$ Corinne Grangette, ${ }^{4}$ Pierre Pochard, ${ }^{1,2,3,5}$ \\ André-Bernard Tonnel, 1, 2,3 and Joël Pestel1, 2,3 \\ ${ }^{1}$ Institut National de la Santé et de la Recherche Médicale (INSERM) U 416, Institut Fédératif de Recherche 17 (IFR 17), \\ Institut Pasteur de Lille, 59019 Lille, France \\ ${ }^{2}$ Institut Pasteur de Lille, 59019 Lille, France \\ ${ }^{3}$ Université de Lille 2, 59800 Lille, France \\ ${ }^{4}$ Bactéries Lactiques et Immunité des Muqueuses, Institut Pasteur de Lille, 59019 Lille, France \\ ${ }^{5}$ The Department of Immunology, Faculty of Medicine, University of Manitoba, Basic Medical Sciences Building, Winnipeg, \\ $M B$, Canada R3E OW3
}

Received 10 October 2006; Revised 4 December 2006; Accepted 6 December 2006

Recommended by Abdelali Haoudi

Lactic acid bacteria (LAB) are Gram positive nonpathogenic commensal organisms present in human gastrointestinal tract. In vivo, LAB are separated from antigen-presenting cells such as dendritic cells (DC) by the intestinal epithelial barrier. In this study, the impact of one LAB strain (Lactobacillus casei ATCC393) on human monocyte-derived DC from allergic and healthy donors was assessed by using a polarized epithelium model. Confocal and flow cytometer analyses showed that immature DC efficiently captured FITC-labelled L. casei through the epithelial layer. After interaction with L. casei, DC acquired a partial maturation status (i.e., CD86 and CD54 increase) and increased their interleukin (IL)-10 and IL-12 production. Interestingly, after activation by $L$. casei in the presence of experimental epithelium, DC from allergic patients instructed autologous naïve CD4 ${ }^{+} \mathrm{T}$ cells to produce more interferon $-\gamma$ than without the epithelium. Thus by modulating human DC reactivity, LAB and intestinal epithelium might modify $\mathrm{T}$ cell immune response and regulate the development of allergic reaction.

Copyright (c) 2007 Céline Ratajczak et al. This is an open access article distributed under the Creative Commons Attribution License, which permits unrestricted use, distribution, and reproduction in any medium, provided the original work is properly cited.

\section{INTRODUCTION}

Dendritic cells (DC), known as professional antigen-presenting cells, are involved in the regulation of mucosal immune responses. In peripheral tissues, contact with antigen induces a maturation process and the migration of DC to secondary lymphoid organs, where they induce the differentiation of naïve $\mathrm{T}$ cells $[1,2]$. The induced profile (i.e., Th1, Th2, or regulatory) depends on the nature of the signals received and delivered by DC [3]. In atopic patients, DC play a pivotal role in the development and the maintenance of allergic diseases characterized by a predominant Th2 profile $[3,4]$.

The increased risk of allergic diseases observed in industrialized countries was suggested to be related to western life style characterized by a reduced overall exposure to microbial stimulation in infancy [5-7]. Postnatal exposure to microbial antigens elicits preferentially $\mathrm{Th} 1$ or T regulatory responses, which have been suggested to counterbalance Th2- polarized cytokine production in neonates. Insufficient early microbial exposure may favor the persistence of Th2-type cytokines production allowing the potential development of allergy. The intestine is one of the major immune organs of the body where DC can encounter bacteria $[8,9]$. The predominant sites of antigen sampling are the Peyer patches, where intestinal DC interact directly with luminal bacteria by passing their dendrites between epithelial tight junctions or after transport of bacteria through $\mathrm{M}$ cells $[10,11]$.

Some commensal organisms are used as probiotics, that is, live microbial food ingredients with health-promoting properties [12]. Recent studies suggest that healthy gut microbiota may have a crucial role for the maturation of the immune system to nonallergic mode. The intestinal flora of allergic children is less often colonized with lactobacilli in comparison with nonallergic children [13]. A clinical study demonstrates that perinatal administration of probiotic bacteria (Lactobacillus GG) halved the later development 
of atopic eczema in high-risk children [14, 15]. This effect may be due to the anti-inflammatory properties of probiotic bacteria. Consumption of Lactobacillus GG by children with atopic dermatitis has been reported to enhance the generation of interleukin (IL)-10 in serum [16]. Moreover oral feeding of mouse with heat-killed Lactobacillus casei (strain shirota) inhibited specific IgE production [17]. As DC inhabiting the gut, mucosa are constantly in close vicinity to microorganisms, the intestinal flora may exert regulatory effects through DC modulation. Lactobacilli were reported to regulate mouse DC surface molecule expression and cytokine production [18]. We previously demonstrated that three different LAB strains were able to inhibit the secretion of Th2 cytokines by peripheral blood mononuclear cells from allergic donors [19]. Moreover, we confirmed for one of the strain (L. plantarum) the inhibition of the Th2 response induced by Der $\mathrm{p}$ 1-pulsed DC from allergic patients in vitro. This was associated with increased IL- 12 secretion by DC, reduced Th2 cytokine production (IL-4, IL-5), and increased production of Th1 cytokine (interferon (IFN)- $\gamma$ ) by autologous $\mathrm{T}$ cells [20].

The presence of LAB in the intestinal environment might be an important factor required to avoid the development of the allergy-associated Th2 response. In view of the critical importance of DC in the regulation of the immune response, we analyzed the reactivity of human monocytederived DC to the LAB L. casei (ATCC 393) by using a welldefined experimental model of intestinal epithelium. Thus the effect of a L. casei strain on activation patterns of DC from allergic and healthy donors was investigated and the impact on T cell-dependent cytokine production was evaluated.

\section{MATERIALS AND METHODS}

\subsection{DC and T lymphocytes preparation}

\subsubsection{Donors}

Blood was collected from allergic patients sensitive to house dust mite (specific IgE antibodies; positive skin prick tests towards Dermatophagoides pteronyssinus (Dpt) (RAST class > 3); total serum IgE $>250 \mathrm{kU} / \mathrm{mL}$ ) and from healthy donors (total IgE level $<20 \mathrm{kU} / \mathrm{L}$; specific anti-Dpt antibodies $<0.35 \mathrm{kU} / \mathrm{L})$.

\subsubsection{Cell preparation}

Monocyte-derived DC were generated from blood monocytes purified by positive selection using monoclonal antiCD14 antibodies coupled to magnetic microbeads (Miltenyi Biotech, Bergsch Gladbach, Germany) as described [20]. Cells were cultured at $1 \times 10^{6}$ cells $/ \mathrm{ml}$ for 5-6 days in complete medium containing $25 \mathrm{ng} / \mathrm{ml}$ granulocyte-macrophage colony stimulating factor (GM-CSF) (Preprotech, London, $\mathrm{UK}$ ) and $10 \mathrm{ng} / \mathrm{ml} \mathrm{IL-4} \mathrm{(R \& D} \mathrm{system,} \mathrm{Oxon,} \mathrm{UK)} \mathrm{to} \mathrm{obtain}$ immature DC. At the end of the culture, $95 \%$ of the population is CD1a ${ }^{+} \mathrm{HLA}-\mathrm{DR}{ }^{+} \mathrm{CD} 80 / \mathrm{C} 86^{\text {low }}$.
Naive CD4 ${ }^{+} \mathrm{T}$ cells were isolated from the eluted CD14 ${ }^{-}$ cell fraction by negative selection using a $\mathrm{CD} 4^{+} \mathrm{CD} 45 \mathrm{RA}^{+}$ $\mathrm{T}$ cell isolation kit (Miltenyi Biotech, Germany) (purity > 95\%) and frozen until use.

\subsection{Caco2-DC Transwell coculture system}

To mimic the intestinal barrier, we used an in vitro Transwell coculture system as described [10]. Caco2 cell line was grown in Dulbecco's MEM (Cambrex Bio Sciences, Verviers, Belgium) supplemented with 10\% heat-inactivated fetal calf serum (Invitrogen, Paisley, UK), 1\% nonessential amino acid (Gibco BRL, UK), and antibiotics. Cells were seeded on the upper face of $6.5 \mathrm{~mm}$ filters $(3 \mu \mathrm{m}$ pore Transwell filters, Corning Incorporated, Acton, MA) for 15 days until a transepithelial resistance (TER) of $\sim 300 \Omega / \mathrm{cm}^{2}$ was achieved. Transwell filters were turned upside-down, and immature DC $\left(1 \times 10^{6}\right)$ were added for $3 \mathrm{hr}$ on the filter facing the basolateral membrane of the epithelium to allow cell attachment. Filters were replaced into 24 -well plates. TER was checked to be unchanged during the coculture with DC and after L. casei stimulation (Grangette personal observation) as described [21].

\subsection{Preparation of bacteria}

L. casei ATCC 393 was prepared as previously described [20]. Briefly, the bacteria were cultured overnight in MRS broth medium (Difco, Detroit, MI), at $37^{\circ} \mathrm{C}$. The bacterial suspension was diluted at 1:20 in fresh medium and further cultured until exponential phase. After washing, bacteria were resuspended in PBS containing 20\% of glycerol and stored at $-80^{\circ} \mathrm{C}$ before using. The bacteria concentration was determined as described [20].

As live and killed LAB were not different in their capacity to regulate peripheral blood mononuclear cells (PBMC) or DC stimulation ([19, 20], Grangette personal observation), we used killed LAB obtained after fixation by $45 \mathrm{~min}$ incubation in endotoxin-free PBS 4\% paraformaldehyde (PFA). These killed LAB were stored at $+4^{\circ} \mathrm{C}$ until use.

\subsection{Uptake analysis}

\subsubsection{FITC-labelled bacteria}

Fixed bacteria were resuspended in RPMI ( $1 \mathrm{ml})$ and incubated with ethanol $(2 \mathrm{ml}, 70 \%)$ for $1 \mathrm{~h}$ at room temperature. After centrifugation ( $2500 \mathrm{~g}, 15 \mathrm{~min}$ ), bacteria were suspended in carbonate/bicarbonate $(\mathrm{pH}=9.7)$ buffer and incubated with $0.1 \mathrm{mg} / \mathrm{ml}$ fluorescein isothiocyanate (FITC) (Sigma, Germany) for $1 \mathrm{~h}$, with constant stirring. After washing in PBS $0.1 \%$ gelatine, bacteria were stored in RPMI at $-20^{\circ} \mathrm{C}$ before use. FITC-labelled bacteria were added on the apical side for 24 or $48 \mathrm{~h}$ at the dose of DC/bacteria: 1/10, $1 / 100$. TER were checked to be unchanged during this time.

\subsubsection{Flow cytometer analysis}

Monocyte-derived DC from allergic $(n=2)$ or healthy $(n=$ 2 ) donors, adherent or not to the filter, were collected and 


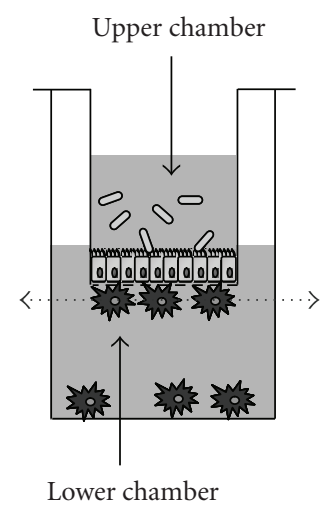

(a)

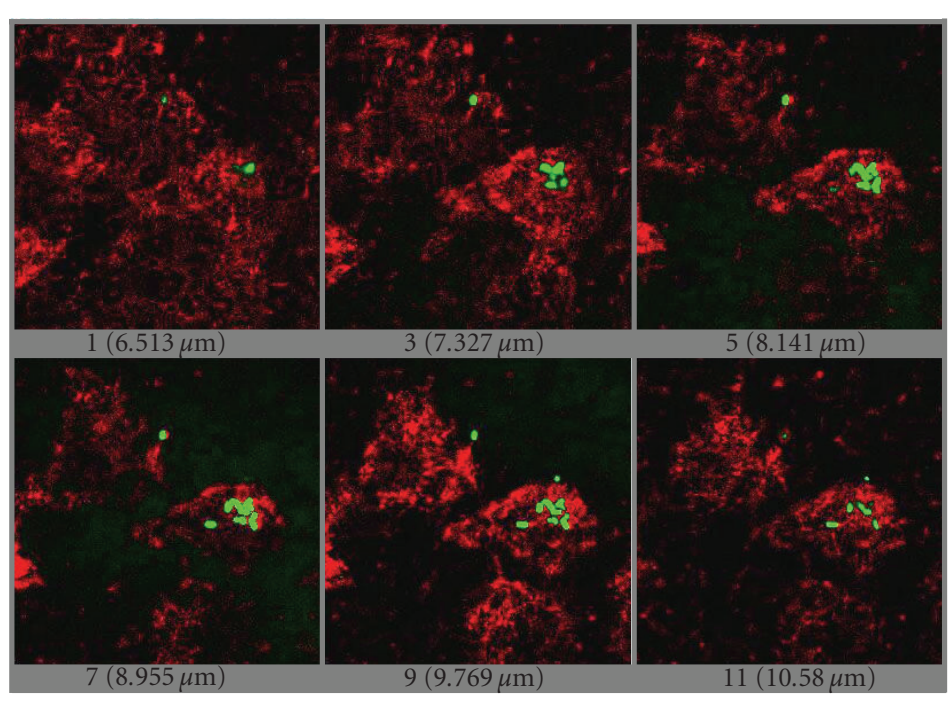

(b)

FIgUre 1: Confocal analysis of FITC-labelled L. casei uptake by adherent DC. (a) Schematic view of the DC/epithelial cell culture model. The dotted arrow indicates the section where the analysis was done. (b) The pictures represent different sections of the same DC and show the colocalization of FITC-bacteria into the cytoplasm of DC.

immediately analyzed by FACScalibur (Becton Dickinson, San Diego, CA).

\subsubsection{Cell staining for confocal microscopy}

After $48 \mathrm{~h}$ of culture, Transwell filters were washed and fixed 30 min in PFA (4\%). After 15 min treatment with PBS 0.5\% Triton (Hopkin \& Williams) and 30 min saturation with human serum (2\% in PBS), filters were incubated either with monoclonal anti-human CD11c antibody coupled to Phycoerythrin (PE) or with an irrelevant antibody (Becton Dickinson) for $30 \mathrm{~min}$. After washing, filters mounted with Fluoprep (Biomérieux SA, France) were analyzed with confocal laser scanning microscope (SP2 AOBS, LCS software, Leica, Wetzlar, Germany).

The dose of 100 bacteria for 1 DC, allowing the highest uptake intensity in preliminary studies, was chosen for all the experiments with the epithelium (data not shown).

\subsection{DC activation}

After $48 \mathrm{~h}$ of culture with bacteria, monocyte-derived DC from allergic $(n=6)$ or from healthy $(n=7)$ donors were harvested for phenotype analysis and their supernatants collected. Only one test per individual was performed in each group.

\subsubsection{DC surface marker analysis}

Monocyte-derived DC adherent or nonadherent to the filter were washed in PBS and incubated for $30 \mathrm{~min}$ at $4^{\circ} \mathrm{C}$ with different monoclonal antibodies (mAbs) : FITC-conjugated
anti-CD86, anti-HLA-DR, and PE-conjugated anti-CD80, anti-CD54 or irrelevant mAbs (Becton Dickinson). Cells were fixed in PBS 1\% PFA and analyzed using a FACScalibur (Becton Dickinson). Variations in DC phenotype were expressed as the difference between mean fluorescence intensity (MFI) minus the isotype control MFI ( $\triangle \mathrm{MFI})$.

\subsubsection{Cytokine production by $D C$}

DC supernatants were harvested from the lower chamber of the Transwell $48 \mathrm{~h}$ following stimulation and assayed for the presence of IL-10 or IL-12 (IL-12 p70) by specific ELISA (Diaclone, France). The sensitivity of both assays was $5 \mathrm{pg} / \mathrm{ml}$.

\subsection{T cell activation}

\subsubsection{DC-T coculture}

After 24 hours of culture with bacteria, monocyte-derived DC (allergic: $n=5$; healthy: $n=5$ ) activated in the Transwell system and adherent or not to the filter were harvested from the lower chamber (Figure 1(a)). After washing, DC were resuspended in complete RPMI medium $\left(10^{5} / \mathrm{ml}\right)$ and cultured with autologous $\mathrm{CD} 4^{+} \mathrm{CD} 45 \mathrm{RA}^{+} \mathrm{T}$ cells $\left(10^{6} / \mathrm{ml}\right)$ (ratio: 1 $\mathrm{DC} / 10 \mathrm{~T}$ lymphocytes) for 5 days. Only one test per individual was performed in each group.

\subsubsection{Cytokine production by T cells}

Supernatants were collected and assayed for IL-5 (PharMingen), IL-10, and IFN- $\gamma$ (Diaclone) by specific ELISA (sensitivity $=5 \mathrm{pg} / \mathrm{ml}$ ). 


\subsection{Statistical analysis}

Nonparametric statistical analyses were performed with paired samples and the permutation tests (STATEXACT, Cytel Software, MA). $P$ values of .05 or less were considered statistically significant.

\section{RESULTS}

\subsection{DC are able to capture L. casei through the intestinal epithelium}

To evaluate the uptake of lactic acid bacteria (LAB) by DC through a human intestinal epithelium, DC from healthy or allergic donors were incubated with FITC-labelled L. casei for 24 or 48 hours in the Transwell coculture system. DC adherent and nonadherent to the filter were harvested and analyzed separately. The number of DC adherent to the filter was slightly increased with DC from healthy donors compared to allergic patients after $L$. casei stimulation $(59800 \pm 28200$ and $33900 \pm 2200$ adherent cells per well, resp.), whereas unstimulated DC from healthy and allergic donors similarly adhere to epithelium $(20417 \pm 4641$ and $17000 \pm 5778$, resp.). Both in allergic and healthy donors, the capture of FITC-bacteria by DC directly adherent to the epithelium increased between 24 and $48 \mathrm{~h}$. In contrast, nonadherent DC captured fewer bacteria and only at $48 \mathrm{~h}$. For the analyzed donors, the uptake of $L$. casei by DC was lower for allergic compared to healthy donors (Figure 2). Higher percentages of FITC-positive cells were detected when DC were directly incubated with bacteria, without epithelium (data not shown).

The bacteria uptake through the intestinal epithelium was further confirmed by confocal microscopy. Different sections of the same adherent DC detected with an anti-CD11c antibody (Figure 1(a)) clearly showed a colocalization of FITC-labelled L. casei into the DC cytoplasm (Figure 1(b)).

\subsection{DC acquire a moderate maturation status upon L. casei stimulation through the intestinal epithelium}

To determine whether maturation of DC by L. casei, in the presence of the epithelium, is associated with phenotypic changes; the expression of CD80, CD86, HLA-DR, and CD54 (intercellular adhesion molecule (ICAM)-1) was assessed. L. casei induced a low increase in the expression of the costimulatory molecules CD86 $(P<.05$ for adherent and nonadherent DC from allergic patients $)$ and CD54 $(P<.05$ for adherent DC from allergic donors) on DC from healthy and allergic donors, whether they were adherent or not to the epithelium. The expression of MHC II (HLA-DR) and CD80 was not modified by the stimulation with $L$. casei on DC from both allergic and healthy donors (Figure 3). These results suggest that $L$. case $i$ induces a moderate maturation of DC in presence of the epithelium.

\subsection{Cytokine production by L. casei-stimulated DC}

The production of IL-10 and IL-12, involved in the orientation of the immune response, was analyzed. DC from healthy
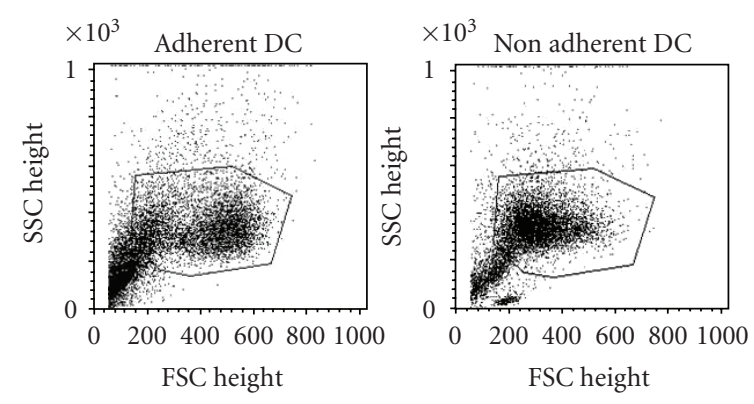

(a)

Allergic patient

Healthy donor

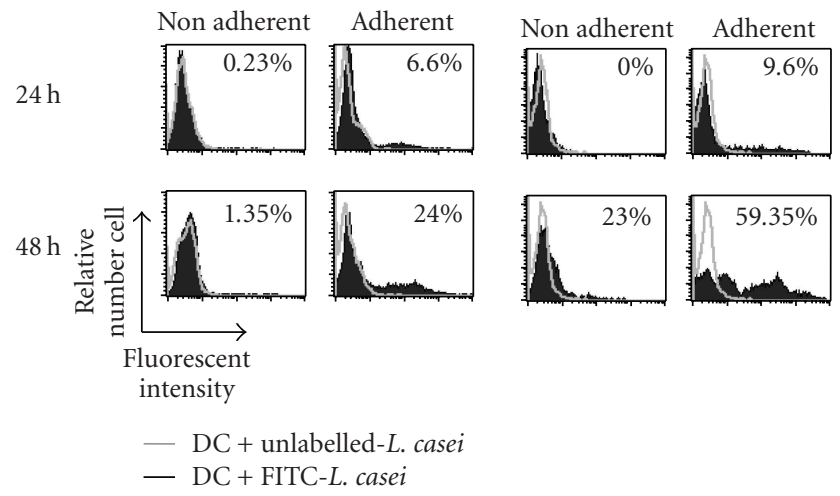

(b)

FIGURE 2: DC take up FITC-labelled L. casei through an intestinal epithelial layer. Monocytes from allergic patients and healthy donors were differentiated in DC in the presence of GM-CSF and IL-4 for 56 days. Cells were then pulsed with unlabelled or with FITC-labelled L.casei (ratio bacteria/DC: 100/1) for 24 or 48 hours in the presence of an intestinal epithelial layer. DC, adherent and nonadherent to the filter, were harvested and analyzed by flow cytometry. (a) The percentage of FITC-positive cells is evaluated into the gate represented on the dot plots. (b) Open histograms represent the fluorescence of DC incubated with unlabelled $L$. casei, and closed histograms represent the capture of FITC-labelled L. casei by DC. The percentages of FITC-positive cells are indicated. One representative experiment is shown for both donor types.

donors incubated with $L$. casei significantly produced IL-10 and IL-12 $48 \mathrm{~h}$ after the stimulation, with similar levels in the presence or in the absence of the intestinal epithelium (Figure 4(a)). In contrast, DC from allergic patients incubated with $L$. casei only slightly increased IL-10 and IL-12 production in the absence of the epithelium, whereas the secretion of these two cytokines was amplified in the presence of the epithelial layer $(P<.05)$ (Figure $4(\mathrm{~b}))$, suggesting a role of the epithelium in the $L$. casei-induced cytokine production by DC from allergic donors.

\subsection{Cytokine production by naive $C D 4^{+} T$ cells}

To evaluate the effect of $L$. casei on the orientation of the response induced by DC from allergic and healthy donors, the 
Allergic donors
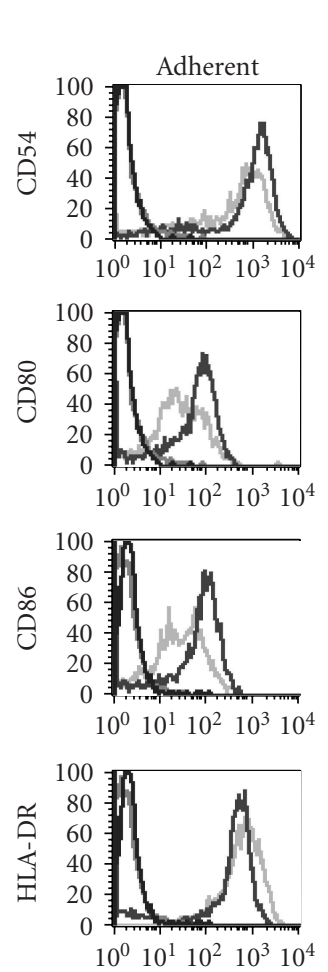

(a)
Allergic donors
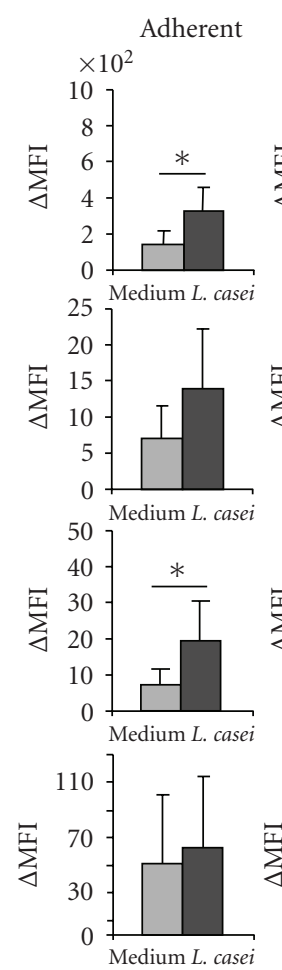

(b)
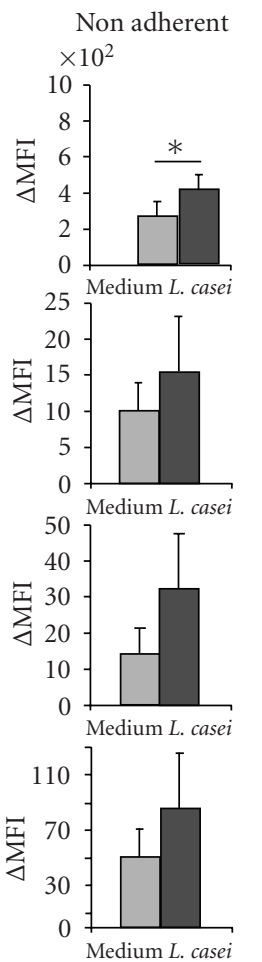

)
Healthy donors

Healthy donors

FIGURE 3: Effect of L. casei stimulation on DC phenotype. Monocyte-derived dendritic cells from house dust mite sensitive-patients (a) and (b) and from healthy donors (c) and (d) were exposed (dark grey line) or not (grey line) to L. casei for 48 hours in the Transwell model. (a) and (c) Adherent DC were analyzed by flow cytometry for CD80, CD86, HLA-DR, and CD54 expression. the black line represents the reactivity of fluorochrome-matched isotype control mAbs. One representative experiment (out of 6 and 7 , for allergic and healthy donors, resp.) is shown. (b), (d) The mean fluorescence intensity $(\triangle \mathrm{MFI})$ of the expression of each marker by adherent and nonadherent DC after stimulation with medium, and L.casei is represented for both allergic ((b), $n=6)$ and healthy donors $((\mathrm{d}), n=7) .{ }^{*} P<.05$.

production of IFN- $\gamma$ (Th1 cytokine), IL-5 (Th2 cytokine), and IL-10 (cytokine produced by some regulatory T cells) by autologous naive $\mathrm{T}$ cells was analyzed. As no differences were detected in the maturation status between adherent and nonadherent DC and as L. casei capture was more efficient in adherent DC, adherent DC were chosen for T cell stimulation.

Without epithelium, L. casei mainly increased the IFN$\gamma$ production by naive T cells instructed by DC from healthy donors $(62.40 \pm 34.88$ compared to $39.45 \pm 26.13$ for medium condition). IL-5 and IL-10 production by T cells was less increased. No increase in these cytokine levels was detected with $L$. casei-activated DC from allergic donors. In healthy donors, the sole presence of $\mathrm{Caco} 2$ epithelial layer (without $L$. casei stimulation) decreased the IFN $-\gamma$ production by DC-instructed T cells $(5.35 \pm 5.58 \mathrm{ng} / \mathrm{ml}$ with the epithelium compared to $39.45 \pm 26.13 \mathrm{ng} / \mathrm{ml}$ without the epithelium). In contrast, for all cytokine production, the increase induced by $L$. casei-stimulated DC from healthy or allergic donors was further enhanced if DC were conditioned by the epithelium. The increase in cytokine production for $\mathrm{T}$ cells activated by $L$. casei-stimulated DC was more pronounced for IFN- $\gamma(26.75 \pm 8.02 \mathrm{ng} / \mathrm{ml}$ for the $L$. casei condition compared to $9.72 \pm 10.41 \mathrm{ng} / \mathrm{ml}$ for the medium condition for allergic patients; $48.60 \pm 16.68 \mathrm{ng} / \mathrm{ml}$ for the $L$. case $i$ condition compared to $5.35 \pm 5.58 \mathrm{ng} / \mathrm{ml}$ for healthy donors). The increase in cytokine production for allergic donors reached similar levels to healthy donors for IL-5 and IL-10, whereas IFN- $\gamma$ levels remained higher for healthy donors (Figure 5).

\section{DISCUSSION}

The mucosal immune system is continuously exposed to dietary and microbial antigens and needs to react with appropriate immune responses. Compelling evidence suggested that appropriate microbial colonization of the gut is important in providing signals to prevent the overexpression of Th2-dominated atopic responses [22]. In the last few years, the potential role of selected probiotic strains in the prevention of allergic diseases has become more evident. Nevertheless the mechanism underlying these properties remains unknown. Intestinal epithelial cells permanently interact with the luminal content, including the commensal flora, and the 
Healthy donors

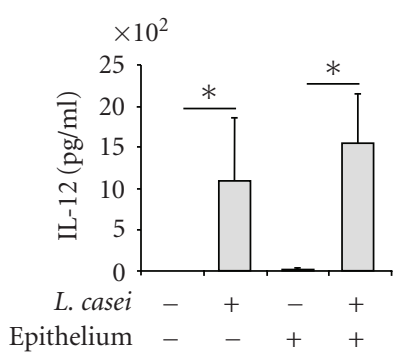

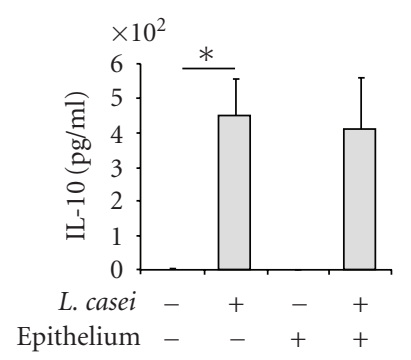

(a)

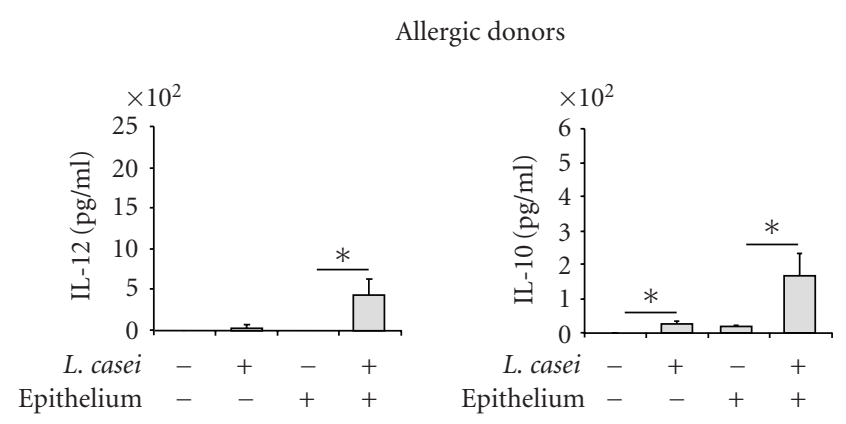

(b)

FIgUre 4: L. casei-stimulated DC produce IL-12 and IL-10. Monocytes-derived DC from healthy (a) and allergic (b) donors were pulsed or not for 48 hours with L. casei through an intestinal epithelial layer or not. Supernatants were collected and the amounts of IL-10 and IL-12 were measured by specific ELISA. Results are expressed as mean $\pm \operatorname{SEM}\left(n=5\right.$ for allergic donors and $n=5$ healthy donors). ${ }^{*} P<.05$.

cellular network of immune cells. Because of their location at mucosal sites and their implication in the initiation of the immune reaction, DC play a key role in this process. In order to evaluate the involvement of DC intestinal environment on their function, we used a well-established model of epithelial cells and DC coculture $[10,21,23]$. We analyzed the effect of a selected $L$. casei strain, which was previously demonstrated to reduce allergen-specific Th2 secretion in vitro [20]. In the present study, we demonstrated that monocyte-derived DC from healthy or allergic donors take up nonpathogenic $L$. casei through an intestinal epithelium. The analysis of the FITC-bacteria uptake in the Transwell model showed that the process is time-dependent, increasing between 24 and $48 \mathrm{~h}$, and higher in healthy donors compared to allergic ones. The number of DC which have captured bacteria through the epithelium was low even after $48 \mathrm{~h}$ in comparison with DC directly interacting with $L$. casei (without the epithelium). Using fluorescent beads, we checked that beads incubated in the upper chamber did not pass through the epithelium. Moreover, because no change in TER was observed, we hypothesize that in our conditions DC open tight junctions and sample bacteria by extending their dendrites through the epithelium without disrupting epithelial integrity as it was previously demonstrated in the same model [10]. This active process may explain the time required to capture bacteria efficiently in the presence of the epithelium. By confocal analysis, we clearly confirmed the bacteria uptake by DC as L. casei colocalized with adherent DC.

By producing cytokines and/or by expressing specific costimulatory molecules, DC can modulate the development of $\mathrm{T}$ cell response and are considered as pivotal cells in the development or the limitation of the allergic reaction. DC phenotype and functions are dependent upon their mucosal environment. In particular, intestinal epithelial cells condition DC to become "noninflammatory" in vitro and may be involved in their capacity to maintain gut homeostasis $[21,24]$. Here we showed that DC from both allergic and healthy donors acquired an intermediate maturation status characterized by a moderate expression of cell-surface cos- timulatory molecules and maturation markers upon stimulation with $L$. casei in the presence of the intestinal epithelium. This intermediate maturation status has previously been described in different experimental settings. The ability of two Gram-positive bacteria, pathogenic Streptococcus pyogenes, and nonpathogenic Lactobacillus rhamnosus to induce monocyte-derived DC maturation has been compared. S. pyogenes was shown to be a more potent stimulator of DC maturation than L. rhamnosus. Indeed, this lactic acid bacteria induced a partial DC maturation, as evidenced by the moderate expression of costimulatory molecules CD80, CD83, and CD86 and a weak cytokine and chemokine response [25]. The same observations were reported with activation by direct contact of human DC by a Gram-negative pathogenic bacteria compared to L. rhamnosus and with activation of murine DC with various strains of Lactobacilli $[18,26]$. Similarly, in a model of intestinal epithelium, activation with $L$. plantarum induced a lower expression of CD80 and CD83 compared with activation with Gram-negative pathogenic bacteria [24]. As costimulatory molecules are involved in contact between DC and T cells during antigen presentation, a moderate expression of these molecules may result in orientation toward a T regulatory pathway [27].

The cytokine microenvironment plays a critical role during $\mathrm{T}$ cell polarization. For example, IL-12 is important to skew $\mathrm{T}$ cell differentiation towards Th1-type response, and IL-10 is associated with immunoregulatory processes $[28,29]$. Here we showed that $L$. casei-induced IL-10, and IL-12 production by DC from allergic donors was lower compared to healthy donors, which may be related to a lower adherence to the epithelium and a lower number of DC which have captured L. casei. However, as this lower production of IL-10 and IL-12 by DC from allergic donors was also obtained after $L$. casei stimulation in the absence of the epithelium, this suggests a dysfunction of DC from allergic compared to healthy donors. Both cytokines were shown to be produced by murine DC stimulated by a mixture of bifidobacteria and lactobacilli (VSL\#3) [30]. We also noticed that, in the presence of the intestinal epithelium, DC from 


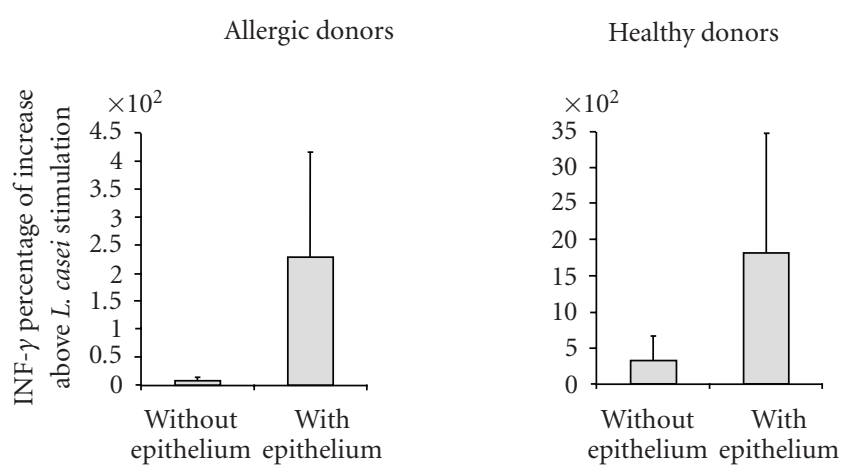

(a)

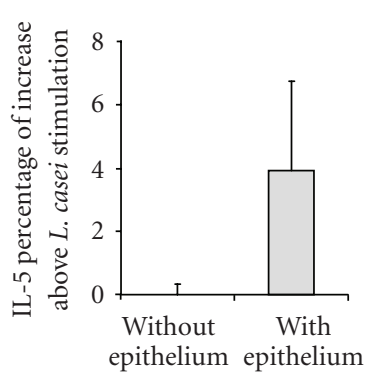

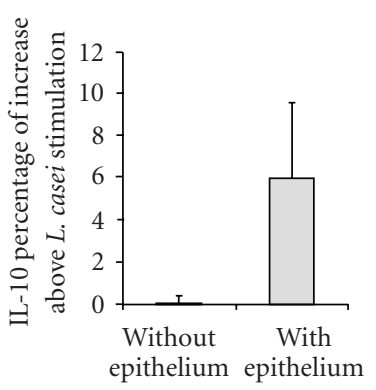

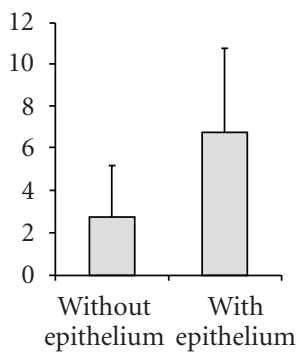

(b)

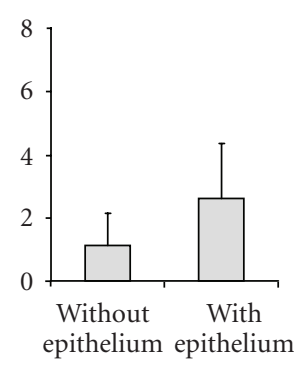

(c)

FIGURe 5: Production of cytokine by naïve CD4 ${ }^{+}$T cells. Monocyte-derived DC from allergic patients and healthy donors were incubated with L. casei or medium only for 24 hours, either directly in contact with cells (without epithelium) or through an intestinal epithelial layer (with epithelium). Adherent DC were harvested from the lower chamber of the Transwell, cultured with naïve autologous CD4 ${ }^{+} \mathrm{T}$ cells for 5 days. Supernatants were collected and the amounts of IFN- $\gamma$, IL-10, and IL- 5 were measured by specific ELISA. Results are expressed as mean \pm SEM of cytokine percentage increase above L. casei stimulation ( $n=5$ for both allergic and healthy donors).

allergic patients produced higher levels of IL-12 and IL-10 compared to cells directly in contact with bacteria. The interactions of $L$. case $i$ with epithelial cells might have an effect on IL-12 and IL-10 secretion by DC from allergic patients, therefore balancing the potential defect in their production. Indeed, some mediators released by epithelial cells might induce "noninflammatory DC," which contribute to maintain gut immune homeostasis, and limit excessive inflammatory reactions like allergy [31]. Consequently, in allergic patients, stimulation with nonpathogenic $L$. casei associated with the anti-inflammatory effect of the epithelium might favor the development of semimature DC, characterized by moderate expression of costimulatory molecules and low cytokine production that could counterbalance the Th2-biased immune response [27, 32].

$\mathrm{T}$ cell activation and polarization of the immune response may be influenced by DC maturation status and DC cytokine production induced by L. casei. In the present study, we showed that the epithelium increased the cytokine production by autologous T cells instructed by $L$ case $i$-activated DC derived from healthy and allergic donors, and especially the IFN $-\gamma$. Increased IFN- $\gamma$ induced by LAB has previously been shown in a system of direct contact with bacteria using DC from allergic and healthy donors [20, 33]. In vivo, another LAB strain (L. plantarum) exhibited Th1 promoting capacity in a murine model of birch pollen allergy [34]. IL-5 and IL-10 production were measured to analyze the effect of LAB activation on the Th2 or on the immunoregulatory responses, respectively. L. casei-pulsed adherent DC conditioned by the intestinal epithelium moderately increased the secretion of IL-5 and IL-10 in both allergic and healthy donors. The increase in IL-5 production is in agreement with a previous study using DC derived from healthy donors and activated by L. plantarum in the presence of an intestinal epithelial monolayer [24]. However, in the absence of the epithelium, L. plantarum has been shown to reduce the Th2 response induced by DC from allergic donors stimulated by the relevant allergen; whilst it did not modify the response in healthy donors [20]. This suggests that LAB may differentially regulate the immune response according to their environment. Selective lactobacilli strains (L. casei and $L$. reuteri) have been demonstrated to drive the generation of regulatory IL- $10^{+} \mathrm{T}$ cells through DC activation in vitro [35]. Moreover, L. rhamnosus has been shown to induce a peripheral hyporesponsiveness in stimulated $\mathrm{CD} 4^{+} \mathrm{T}$ cells [36]. IL-10 is a cytokine known to limit an inflammation due to IFN- $\gamma$ or IL-5 production. Even though, in our experiment, the moderate increased secretion of IL-10 in the coculture of $\mathrm{T}$ cells with $L$. casei-pulsed adherent DC may be due to increased production by DC, the balance between 
IL-10 and IFN- $\gamma$ or IL-5 might regulate potential immune regulatory pathways. Thus, strains of lactobacilli might differentially affect DC and lead to the development of different $\mathrm{T}$ cell responses but each mechanism seems to control the immune homeostasis. Moreover, although DC nonadherent to the filter, that is, not in direct contact with the epithelium, exhibited a similar maturation status compared to adherent DC, nonadherent DC from both allergic and healthy donors failed to increase $\mathrm{T}$ cell cytokine production upon L. casei stimulation (data not shown). These results indicate that the epithelium plays a role in the capacity of $L$. casei-activated $\mathrm{DC}$ to regulate $\mathrm{T}$ cells, even though the sole presence of the epithelium decreases the Th1 response as previously demonstrated [31]. DC in contact with L. plantarum and epithelial cells in the Transwell model have been shown to be more "inflammatory" because of their capacity to release IL-12, IL10 and to promote T cell proliferation, compared to DC activated only by epithelial mediators [24]. The crosstalk between epithelial cells, DC, and LAB might allow on the one hand the establishment of a protective effect against any antigen encountered, vital for combating pathogenic organisms, and on the other hand the limitation of potentially damaging inflammatory immune reactions against endogenous microflora.

In conclusion, our results demonstrate efficient interactions between L. casei and DC through the intestinal epithelium. By modulating DC function and by preserving its capacity to react against harmful pathogenic organisms, $L$. $\mathrm{Ca}$ sei may contribute to maintain the homeostasis of the gut immune system. Finally, by limiting inappropriate immune activation, $L$. casei might prevent or reduce inflammatory responses such as the development of an allergic inflammatory response.

\section{ACKNOWLEDGMENTS}

The authors are grateful to Joëlle Dewulf (BLIM, IPL) and Philippe Marquillies (Inserm U416) for technical assistance and to Bruno Pot for advice. The authors also thank the personnel of the Calmette Hospital for the selection of patients and the blood collection. Céline Ratajczak is a recipient of a grant from Conseil Régional Nord-Pas-de-Calais and Institut Pasteur de Lille. Catherine Duez is a recipient of a grant from the Danone Institute. Joël Pestel is a recipient of a grant from Syndifrais.

\section{REFERENCES}

[1] B. N. Lambrecht, "Allergen uptake and presentation by dendritic cells," Current Opinion in Allergy and Clinical Immunology, vol. 1, no. 1, pp. 51-59, 2001.

[2] M. F. Lipscomb and B. J. Masten, "Dendritic cells: immune regulators in health and disease," Physiological Reviews, vol. 82, no. 1, pp. 97-130, 2002.

[3] H. Hammad, A.-S. Charbonnier, C. Duez, et al., "Th2 polarization by Der p 1-pulsed monocyte-derived dendritic cells is due to the allergic status of the donors," Blood, vol. 98, no. 4, pp. 1135-1141, 2001.
[4] P. G. Holt and J. W. Upham, "The role of dendritic cells in asthma," Current Opinion in Allergy and Clinical Immunology, vol. 4, no. 1, pp. 39-44, 2004.

[5] M. Wills-Karp, J. Santeliz, and C. L. Karp, "The germless theory of allergic disease: revisiting the hygiene hypothesis," $\mathrm{Na}$ ture Reviews Immunology, vol. 1, no. 1, pp. 69-75, 2001.

[6] M. C. Noverr and G. B. Huffnagle, "Does the microbiota regulate immune responses outside the gut?" Trends in Microbiology, vol. 12, no. 12, pp. 562-568, 2004.

[7] S. L. Prescott and J. A. Dunstan, "Immune dysregulation in allergic respiratory disease: the role of T regulatory cells," Pulmonary Pharmacology and Therapeutics, vol. 18, no. 3, pp. 217-228, 2005.

[8] A. Ouwehand, E. Isolauri, and S. Salminen, "The role of the intestinal microflora for the development of the immune system in early childhood," European Journal of Nutrition, vol. 41, supplement 1, pp. 32-37, 2002.

[9] E. Isolauri, S. Salminen, and A. C. Ouwehand, "Microbial-gut interactions in health and disease. Probiotics," Best Practice \& Research Clinical Gastroenterology, vol. 18, no. 2, pp. 299-313, 2004.

[10] M. Rescigno, M. Urbano, B. Valzasina, et al., "Dendritic cells express tight junction proteins and penetrate gut epithelial monolayers to sample bacteria," Nature Immunology, vol. 2, no. 4, pp. 361-367, 2001.

[11] T. Kucharzik, N. Lügering, K. Rautenberg, et al., "Role of M cells in intestinal barrier function," Annals of the New York Academy of Sciences, vol. 915, pp. 171-183, 2000.

[12] S. Salminen, C. Bouley, M.-C. Boutron-Ruault, et al., "Functional food science and gastrointestinal physiology and function," British Journal of Nutrition, vol. 80, supplement 1, pp. S147-S171, 1998.

[13] F. He, A. C. Ouwehand, E. Isolauri, H. Hashimoto, Y. Benno, and S. Salminen, "Comparison of mucosal adhesion and species identification of bifidobacteria isolated from healthy and allergic infants," FEMS Immunology and Medical Microbiology, vol. 30, no. 1, pp. 43-47, 2001.

[14] M. Kalliomäki, S. Salminen, H. Arvilommi, P. Kero, P. Koskinen, and E. Isolauri, "Probiotics in primary prevention of atopic disease: a randomised placebo-controlled trial," The Lancet, vol. 357, no. 9262, pp. 1076-1079, 2001.

[15] M. Kalliomäki, S. Salminen, T. Poussa, H. Arvilommi, and E. Isolauri, "Probiotics and prevention of atopic disease: 4year follow-up of a randomised placebo-controlled trial," The Lancet, vol. 361, no. 9372, pp. 1869-1871, 2003.

[16] T. Pessi, Y. Sütas, M. Hurme, and E. Isolauri, "Interleukin10 generation in atopic children following oral lactobacillus rhamnosus GG," Clinical and Experimental Allergy, vol. 30, no. 12, pp. 1804-1808, 2000.

[17] T. Matsuzaki, R. Yamazaki, S. Hashimoto, and T. Yokokura, "The effect of oral feeding of Lactobacillus casei strain Shirota on immunoglobulin E production in mice," Journal of Dairy Science, vol. 81, no. 1, pp. 48-53, 1998.

[18] H. R. Christensen, H. Frøkiær, and J. J. Pestka, "Lactobacilli differentially modulate expression of cytokines and maturation surface markers in murine dendritic cells," Journal of Immunology, vol. 168, no. 1, pp. 171-178, 2002.

[19] P. Pochard, P. Gosset, C. Grangette, et al., "Lactic acid bacteria inhibit $\mathrm{T}_{\mathrm{H}} 2$ cytokine production by mononuclear cells from allergic patients," Journal of Allergy and Clinical Immunology, vol. 110, no. 4, pp. 617-623, 2002. 
[20] P. Pochard, H. Hammad, C. Ratajczak, et al., "Direct regulatory immune activity of lactic acid bacteria on Der p 1-pulsed dendritic cells from allergic patients," Journal of Allergy and Clinical Immunology, vol. 116, no. 1, pp. 198-204, 2005.

[21] M. Butler, C.-Y. Ng, D. A. van Heel, et al., "Modulation of dendritic cell phenotype and function in an in vitro model of the intestinal epithelium," European Journal of Immunology, vol. 36, no. 4, pp. 864-874, 2006.

[22] B. Björkstén, E. Sepp, K. Julge, T. Voor, and M. Mikelsaar, "Allergy development and the intestinal microflora during the first year of life," Journal of Allergy and Clinical Immunology, vol. 108, no. 4, pp. 516-520, 2001.

[23] A. Parlesak, D. Haller, S. Brinz, A. Baeuerlein, and C. Bode, "Modulation of cytokine release by differentiated CACO-2 cells in a compartmentalized coculture model with mononuclear leucocytes and nonpathogenic bacteria," Scandinavian Journal of Immunology, vol. 60, no. 5, pp. 477-485, 2004.

[24] M. Rimoldi, M. Chieppa, P. Larghi, M. Vulcano, P. Allavena, and M. Rescigno, "Monocyte-derived dendritic cells activated by bacteria or by bacteria-stimulated epithelial cells are functionally different," Blood, vol. 106, no. 8, pp. 2818-2826, 2005.

[25] V. Veckman, M. Miettinen, J. Pirhonen, J. Sirén, S. Matikainen, and I. Julkunen, "Streptococcus pyogenes and Lactobacillus rhamnosus differentially induce maturation and production of Th1-type cytokines and chemokines in human monocytederived dendritic cells," Journal of Leukocyte Biology, vol. 75, no. 5, pp. 764-771, 2004.

[26] H. Braat, E. C. De Jong, J. M. H. Van Den Brande, et al., "Dichotomy between Lactobacillus rhamnosus and Klebsiella pneumoniae on dendritic cell phenotype and function," Journal of Molecular Medicine, vol. 82, no. 3, pp. 197-205, 2004.

[27] M. B. Lutz and G. Schuler, "Immature, semi-mature and fully mature dendritic cells: which signals induce tolerance or immunity?" Trends in Immunology, vol. 23, no. 9, pp. 445-449, 2002.

[28] M. Moser and K. M. Murphy, "Dendritic cell regulation of $\mathrm{T}_{\mathrm{H}} 1-\mathrm{T}_{\mathrm{H}} 2$ development," Nature Immunology, vol. 1, no. 3, pp. 199-205, 2000.

[29] E. L. Lynch, F. F. Little, K. C. Wilson, D. M. Center, and W. W. Cruikshank, "Immunomodulatory cytokines in asthmatic inflammation," Cytokine and Growth Factor Reviews, vol. 14, no. 6, pp. 489-502, 2003.

[30] M. Drakes, T. Blanchard, and S. Czinn, "Bacterial probiotic modulation of dendritic cells," Infection and Immunity, vol. 72, no. 6, pp. 3299-3309, 2004.

[31] M. Rimoldi, M. Chieppa, V. Salucci, et al., "Intestinal immune homeostasis is regulated by the crosstalk between epithelial cells and dendritic cells," Nature Immunology, vol. 6, no. 5, pp. 507-514, 2005.

[32] H. H. Smits, E. C. De Jong, E. A. Wierenga, and M. L. Kapsenberg, "Different faces of regulatory DCs in homeostasis and immunity," Trends in Immunology, vol. 26, no. 3, pp. 123-129, 2005.

[33] M. Mohamadzadeh, S. Olson, W. V. Kalina, et al., "Lactobacilli activate human dendritic cells that skew T cells toward T helper 1 polarization," Proceedings of the National Academy of Sciences of the United States of America, vol. 102, no. 8, pp. 2880-2885, 2005.

[34] A. Repa, C. Grangette, C. Daniel, et al., "Mucosal co-application of lactic acid bacteria and allergen induces counter-regulatory immune responses in a murine model of birch pollen allergy," Vaccine, vol. 22, no. 1, pp. 87-95, 2003.
[35] H. H. Smits, A. Engering, D. Van Der Kleij, et al., "Selective probiotic bacteria induce IL-10-producing regulatory $\mathrm{T}$ cells in vitro by modulating dendritic cell function through dendritic cell-specific intercellular adhesion molecule 3-grabbing nonintegrin," Journal of Allergy and Clinical Immunology, vol. 115, no. 6, pp. 1260-1267, 2005.

[36] H. Braat, J. Van Den Brande, E. Van Tol, D. Hommes, M. Peppelenbosch, and S. Van Deventer, "Lactobacillus rhamnosus induces peripheral hyporesponsiveness in stimulated $\mathrm{CD} 4^{+} \mathrm{T}$ cells via modulation of dendritic cell function," American Journal of Clinical Nutrition, vol. 80, no. 6, pp. 1618-1625, 2004. 


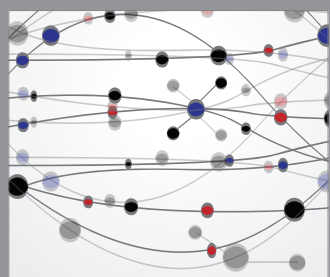

The Scientific World Journal
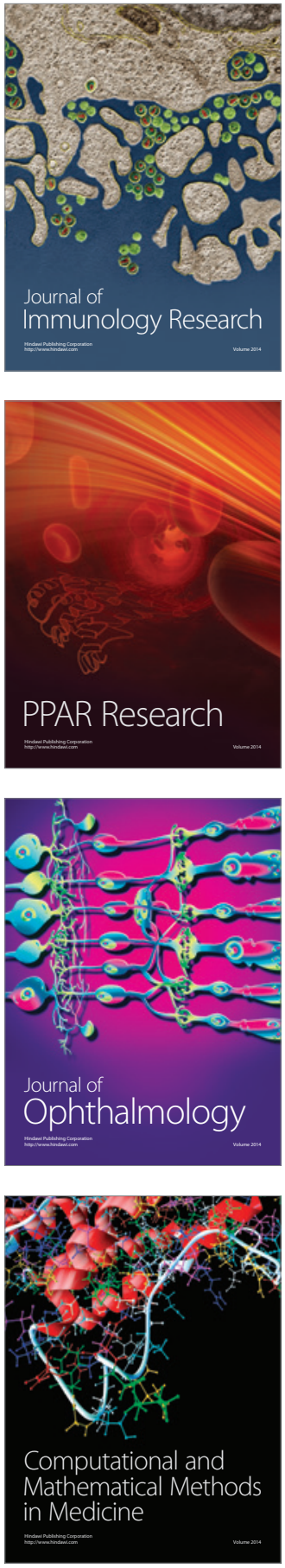

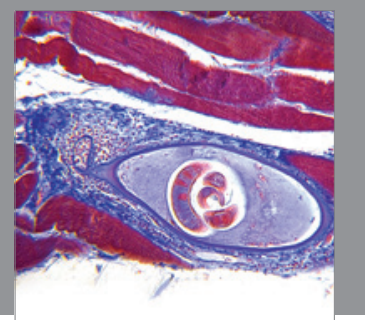

Gastroenterology

Research and Practice
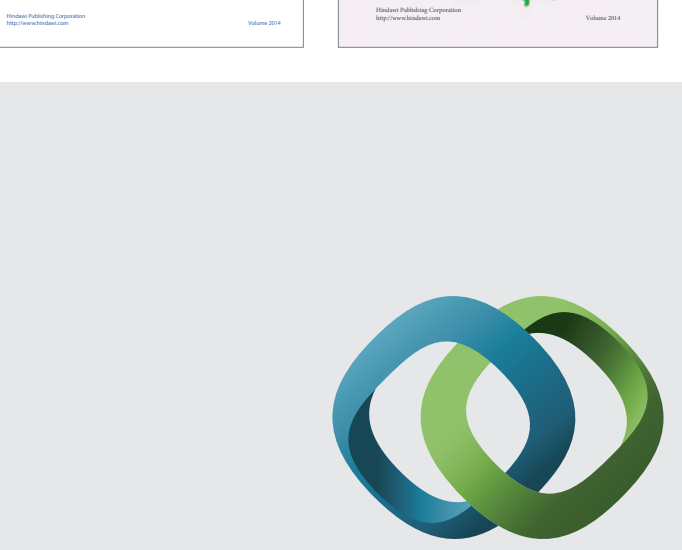

\section{Hindawi}

Submit your manuscripts at

http://www.hindawi.com
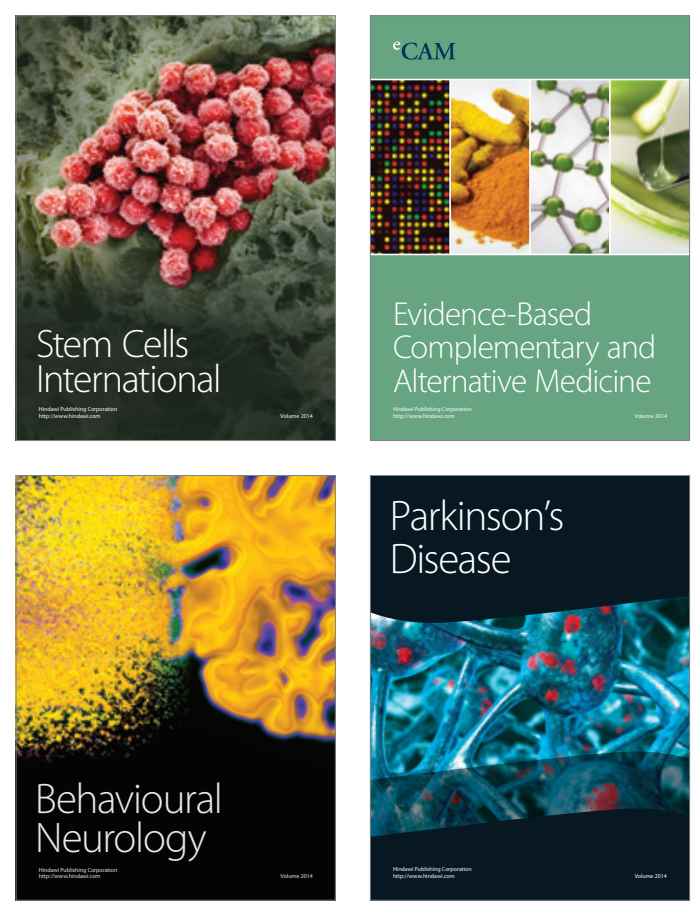

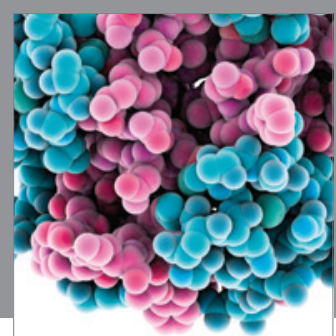

Journal of
Diabetes Research

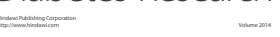

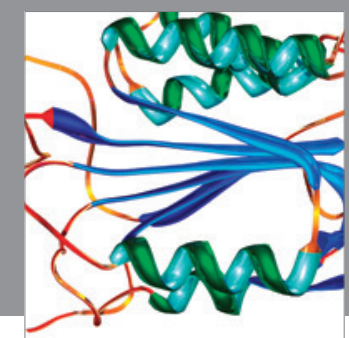

Disease Markers
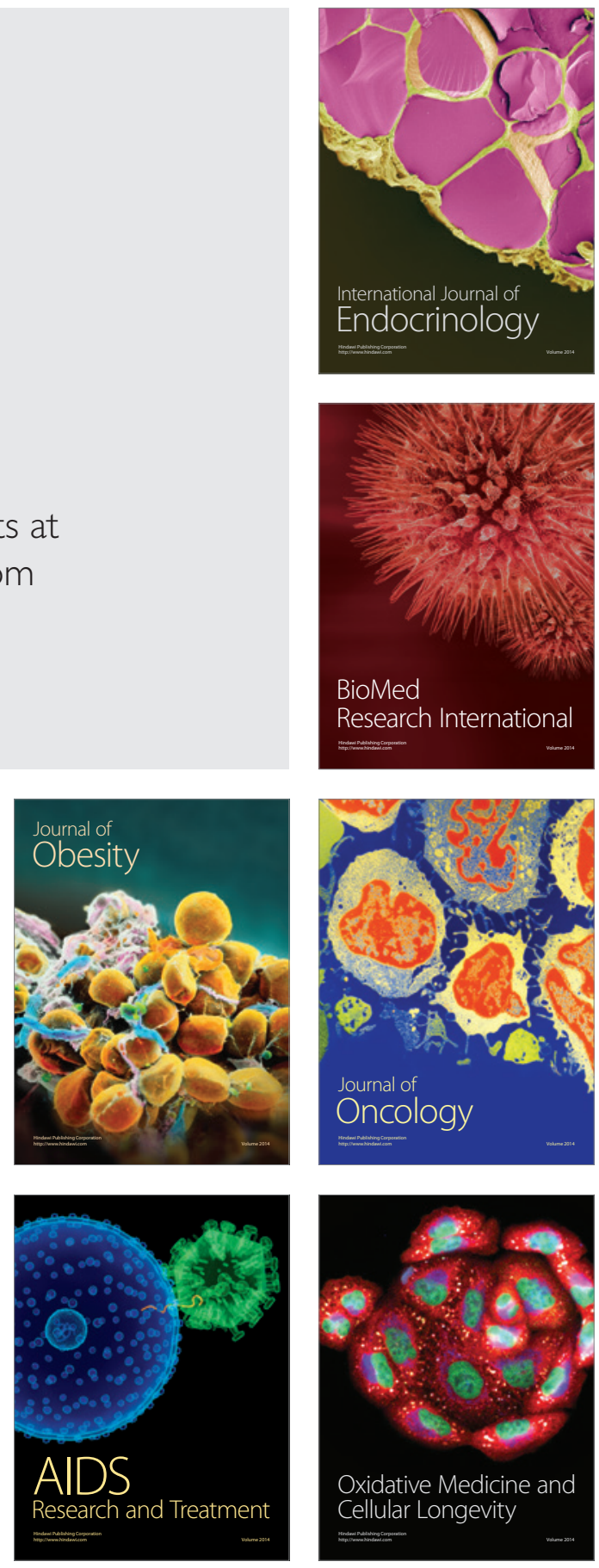